Lent, P.C. \& FiKe, B. (2003) Home ranges, movements and spatial relationships in an expanding population of black rhinoceros in the Great Fish River Reserve, South Africa. South African Journal of Wildlife Research, 33, 109-118.

Morris, D.R. (2009) Black and white survival. Wild Magazine, Winter, 16-28.

Morrison, M., Marcot, B. \& Mannan, R.W. (2006) WildlifeHabitat Relationships. Island Press, Washington, DC, USA.

Reid, C., Slotow, R., Howison, O. \& Balfour, D. (2007) Habitat changes reduce the carrying capacity of HluhluweUmfolozi Park, South Africa, for Critically Endangered black rhinoceros Diceros bicornis. Oryx, 41, 247-254.

Schwartz, C.C., Miller, S.D. \& Haroldson, M.A. (2003) Grizzly bear (Ursus arctos). In Wild Mammals of North America: Biology, Management, and Conservation (eds G.A. Feldhamer, B.C. Thompson \& J.A. Chapman), pp. 556-586. John Hopkins University Press, Baltimore, USA.

Seaman, D.E., Millspaugh, J.J., Kernohan, B.J., Brundige, G.C., RAEDEKE, K.J. \& GitZEN, R.A. (1999) Effects of sample size on kernel home range estimates. Journal of Wildlife Management, $63,739-747$.

\section{Use of black rhino range estimates for conservation decisions: a response to Linklater et al.}

We note the concerns of Linklater et al. (2010) regarding our conclusions for management of black rhinoceros Diceros bicornis in Hluhluwe-iMfolozi Park (Reid et al., 2007). Regarding their methodological issues, we pointed out potential biases in data collection and highlighted that the quality and quantity of information used reduced the quality of our analysis. The reader was therefore forewarned to be cautious in any interpretation.

We used opportunistic data collection throughout. Lack of independence would make any contrast conservative in terms of bias, and the effect of sample size on range size was the opposite to the concern of of Linklater et al. (2010) as the 95\% kernel range increased significantly with sample size (regression: $\left.F_{1,124}=60.2, \mathrm{P}<0.001\right)$. Using only subsets with larger sample sizes, for $\geq 30$ sightings $(n=43$ rhino) mean home range was $29.8 \pm$ SE $1.7 \mathrm{~km}^{2}$ and for $\geq 50$ sightings $(\mathrm{n}=19)$ $34.3 \pm \mathrm{SE} 2.5 \mathrm{~km}^{2}$. While accepting potential data issues (and noting that we used kernel rather than minimum convex polygons), these ranges are substantially larger than those of P.M. Hitchins or K. Adcock/R.H. Emslie (Table 1 in Linklater et al., 2010). We believe it reasonable to conclude that range sizes in general have increased.

Linklater et al. (2010) state 'increases in ranging cannot be used as evidence of deteriorating habitat ... without accounting for inter-specific interactions ... and anthropogenic effects'. We were not the first to propose that rhino range size increased with degrading habitat (Emslie, 1999). Furthermore, we highlighted that changes in range size could be related to disruption of social networks, and that this and effects of elephants Loxodonta africana require further investigation (Reid et al., 2007).

Differential range use by rhino (Reid et al., 2007) and other mega-herbivores between dry and wet seasons is well documented, even in small fenced reserves (Shannon et al., 2006). It is thus not appropriate to use seasonal responses to resource variation as an argument when contrasting ranging across years, as is done by Linklater et al. (2010). They conclude that 'home range size is not a reliable proxy for habitat quality'. While there may be problems with our data this does not negate the potential for home range size to be an indicator for habitat quality, and Linklater et al. (2010) do not present any data to counter this possibility. Our conclusion that 'declining habitat quality ... may have resulted in larger home ranges' was deliberately cautious, and we went on to emphasize the importance of more detailed work examining the potential mechanisms affecting habitat quality for black rhino.

Linklater et al. (2010) are correct that all potential explanations for changes in population productivity of a Critically Endangered species such as black rhino should be investigated. However, our purpose was not to exclude any particular explanation (such as social factors or management interventions) but rather to point out that there may be ecological aspects affecting productivity that need to be investigated. As stated in our original abstract: 'Ongoing review of stocking rates, population performance ... and intervention strategies are necessary to manage black rhino in dynamic savannah ecosystems' (Reid et al., 2007). Simple ecological indices may not necessarily be appropriate as a framework for management planning (e.g. carrying capacity estimates should not be used for black rhino population management; Morgan et al., 2009), and incorporating individual variation in biology is critical (Morgan et al., 2009). Furthermore, interventions should acknowledge the importance of the social clusters that rhino develop (Morgan et al., 2009) and avoid any indiscriminate removal from these groups (Reid et al., 2007; S.R. Morgan, pers. comm.).

\section{Roв SLOTOW}

Biological and Conservation Sciences, Westville Campus, University of KwaZulu-Natal, Bag X54001, Durban 4000, South Africa.E-mailslotow@ukzn.ac.za

CAROLINE REID

Environmental Sciences, University of KwaZulu-Natal, Durban, South Africa

DAVE BALFOUR

Eastern Cape Parks Board, Southernwood, East London, South Africa

OWEN HOWISON

Agriculture and Environmental Affairs, Pietermaritzburg, South Africa

\section{References}

EmsLie, R.H. (1999) The feeding ecology of the black rhinoceros (Diceros bicornis minor) in Hluhluwe-Umfolozi Park, with special reference to the probably causes of the Hluhluwe population crash. $\mathrm{PhD}$ thesis, University of Stellenbosch, Stellenbosch, South Africa. 
Linklater, W.L., Plotz, R.D., Kerley, G.I.H., Brashares, J.S., Lent, P.C., Cameron, E.Z. et al. (2010) Dissimilar home range estimates for black rhinoceros Diceros bicornis cannot be used to infer habitat change. Oryx, 44, 16-18.

Morgan, S.R., Mackey, R.L. \& Slotow, R. (2009) A priori valuation of land use for the conservation of black rhinoceros (Diceros bicornis). Biological Conservation, 142, 384-393.
Reid, C., Slotow, R., Howison, O. \& Balfour, D. (2007) Habitat changes reduce the carrying capacity of Hluhluwe-Umfolozi Park, South Africa, for Critically Endangered black rhinoceros Diceros bicornis. Oryx, 41, 247-254.

Shannon, G., Page, B., Duffy, K. \& Slotow, R. (2009) African elephant home range and habitat selection in Pongola Game Reserve, South Africa. African Zoology, 41, 37-44. 